\title{
Implementing an ecological approach to violence reduction at a forensic psychiatric hospital: approaches and lessons learned
}

\author{
Shannon M. Bader, ${ }^{1 *}$ and Sean E. Evans ${ }^{1,2}$
}

\footnotetext{
${ }^{1}$ Psychology Department, Department of State Hospitals, Patton, California, USA

${ }^{2}$ Psychology Department, La Sierra University, Riverside, California, USA
}

Existing literature on aggression within psychiatric hospitals suggests that treating an aggressive patient's symptoms could be complemented by (a) milieu environments that mitigate violence and (b) hospital-wide policies and procedures that focus on creating a safe environment. Described as an ecological approach, examples of how this broader, situational approach can reduce inpatient violence in psychiatric settings are provided throughout. The authors identify potential barriers to focusing on wards and institutional rules as well as patient treatment. Last, details of how this ecological approach has been implemented at one state hospital in California are provided.

Received 17 September 2014; Accepted 20 February 2015; First published online 17 April 2015

Key words: hospital policy, inpatient, situational variables, systems approach, violence.

\section{Introduction}

For decades, violence and aggressive behavior have been identified as pressing issues facing institutional settings such as psychiatric hospitals and prisons. State psychiatric hospitals in California are no different. The California Department of State Hospitals (DSH) includes 5 hospitals that house an average of 5600 adult patients. During the 2013 calendar year, there were 3377 incidents of aggression perpetrated on other patients and 2596 incidents of aggression directed toward staff members. Approximately $3 \%$ of these assaults were sufficiently severe that the patient or staff member required medical treatment at an outside hospital or emergency room. Consistent with most existing research, attempts to reduce this rate of violence have typically involved medication algorithms or psychosocial methods to treat the aggressive patient. These various interventions stem from the view that violence is due to the psychiatric symptoms, characterlogical features, or behaviors of a disordered patient. The existing research highlights the necessity of a second generation of violence interventions. Specifically, this second generation intervention would encompass a broader view and

* Address for correspondence: Shannon Bader, Psychology Department, Department of State Hospitals, 3102 E. Highland Ave., Patton, CA 92369, USA.

(Email: shannon.bader@psh.dsh.ca.gov) conceptualize inpatient aggression as an ecological problem that combines treatment for aggressive patients with environmental and situational interventions. In addition to treating the patient, environmental interventions treat the ward and treat the hospital in a way that mitigates violence and reduces opportunities for aggression.

Ecology is defined as the study of interactions between individual organisms as well as relationships between organisms and their physical surroundings. This study includes the smallest bacteria living on a leaf to each individual tree to the entire forest. The connections between plants, animals, air, elevation, light, and a myriad of other factors are all analyzed as an integrated whole. ${ }^{1}$ Moreover, small changes in an ecosystem can cascade into ramifications for all other species in an ecosystem. Previous theories of human behavior have also drawn from this broader ecological view. For example, Bronfenbrenner ${ }^{2}$ coined the term "ecological systems theory" to describe how a child's development is influenced by his or her family and school, but also his or her neighborhood, cultural values, statewide economy, and country's political system. Aggression within hospitals, we argue, is related to patients' psychiatric symptoms as well as their interactions with other patents, staff members, the ward milieu, and hospital policies, similar to the delicate balance of ecosystems. After reviewing the existing research on the role of 
environment in hospital wards and hospitals, barriers to adopting an ecological approach are identified, and an example of one hospital's attempt to implement an ecological approach is described.

\section{Literature Review}

The environment of psychiatric hospitals involves numerous variables that have a relationship to aggression. Recent literature reviews on situational and environmental factors related to violence in an institutional setting found existing research support for a relationship between inpatient aggression rates and ward organization, patient populations, staff mixture, hospital management styles, and other environmental variables. ${ }^{3,4}$

For example, patients are often admitted onto a ward using a "one patient out, one patient in" system. Although this method maximizes hospital capacity, it does not allow analyses of the mixture of patients residing on that ward together. An ecological view would assess the ward as an ecosystem with a delicate balance. Cooke and Wozniak ${ }^{5}$ argue that facilities without a systematic method to assess the potential violence of incoming patients and then adjust the mix of population on wards accordingly are at risk of greater violence. Specifically, age, diagnoses, and acuity of the patient population on a certain ward may all influence the rate of aggressive incidents. Research from prisons has demonstrated that younger prison populations have been associated with higher levels of violence, and a heterogeneous mix of ages within a housing unit has been shown to decrease rates of aggression. ${ }^{6,7}$ Palmstierna et $a l^{8}$ found that an increased number of patients on a ward significantly increased aggressive behavior, especially for patients who were diagnosed with a psychotic spectrum disorder. These authors suggest that the coping and stress management needed to reduce feeling crowded may be compromised in individuals experiencing severe mental illness and result in the reported increased rate of violence in psychiatric hospitals. This finding also suggests that a mix of patient diagnoses on a ward may assist in lowering rates of aggression. Again, an ecological view would treat the individual patient's symptoms while simultaneously attempting to reduce aggression rates through management of the number and type of patients designated to live in close quarters.

In addition to the blend of patients, the staff members working are also a significant piece of the ecological system of a psychiatric ward. Numerous studies have found a relationship between staff member age or experience and aggression. ${ }^{9-14}$ Some authors have suggested that a heterogeneous mix of staff members, both newly hired and those with extensive experience working together on the same shift, could reduce the rate of violence. ${ }^{15} \mathrm{~A}$ hospital's inability to recruit and retain the appropriate number of qualified and motivated staff members increases the risk for violence. ${ }^{5}$ As they state, under-staffing as well as high turnover and improperly trained staff lead to reduced morale and poor fidelity to risk-reducing policies or procedures. A ward with a chronically new or understaffed workforce often results in a destabilized unit that is prone to increased violence. For example, recent analyses from one of the DSH hospitals over a 4-year period suggested that both the rate and severity of violent incidents increased when staff members were working an overtime shift. Out of all 5219 incidents at the one hospital, 43.3\% ( $\mathrm{N}=2260)$ occurred when all regularly scheduled staff members were on duty and $57 \%$ ( $\mathrm{N}=2959$ ) occurred with one or more staff working an overtime shift. The same pattern was seen with severe incidents; out of the 153 severe incidents, $37.9 \%(\mathrm{~N}=58)$ occurred when all regularly scheduled staff members were on duty and $62.1 \%(\mathrm{~N}=95)$ occurred when one or more overtime staff were present. ${ }^{16}$ In addition to the number and experience of staff members present, numerous studies have identified that poor communication, patients reporting that they do not feel heard, and denial of privacy are related to aggressive acts. ${ }^{5,17}$ The ecological view would argue that repeated training for all direct care staff, sufficient staffing, and progressive discipline for staff members who show a repetitive pattern of poor-quality relationships with patients are just as important as the medicine provided for patients to maintain a milieu environment that fosters psychiatric recovery and reduces or mitigates risk for violence.

Poor structure and organization on psychiatric wards has also been linked to increased violence. ${ }^{18-20}$ Wards with lower rates of violence have been found to have consistent, reliable schedules and routines, clearly defined staff roles, a committed and active psychiatrist, trusting and calm relationships between staff members and patients, and therapeutic activities available. Wards with higher rates of violence have demonstrated haphazard or unreliable schedules and routines, poor teamwork and diffusion of responsibility, an uninvolved psychiatrist that was rarely present, a perception that the patients were dangerous and should be feared, little interaction between patients and staff members, and few opportunities for therapeutic activities. $^{20}$ The ward's structure, routine, and available treatment opportunities are happening around the patients and perhaps influencing the severity or frequency of psychiatric symptoms. A narrow focus on treating the patient's symptoms will miss the important interaction between the patient and the ward environment. Thinking in terms of ecology, unstructured psychiatric wards with poor interactions between staff and patients result in competition for scarce clinical resources, anxiety about when the next opportunity for a fresh air break may come, or concerns about whether the new unstable patients will be treated before they become aggressive toward you. 
Extensive changes are not always needed to impact institutional violence, and often, small environmental changes have reduced violence. Baldwin ${ }^{21}$ found a statistically significant reduction in physical violence when the furniture in the communal area was rearranged to promote social interaction between patients. After banning the sale of caffeinated drinks, but no other changes, one hospital saw a significant decline in aggressive acts. ${ }^{22}$ The physical environment of a treatment ward may also influence the rates of aggression. For example, sensory overload, from excessive sound or noise, has been identified as a precipitant of violence. ${ }^{9,10}$

Hospital management styles also appear to influence the rate of violence in institutional settings. Cooke and Wozniak $^{5}$ have suggested that poor information systems can increase a hospital's risk for aggression. Specifically, any procedures that limit staff members' ability to quickly access key information regarding a patient result in poor milieu management. If a patient is currently threatening and imminently aggressive, the development of an effective crisis plan to reduce risk is less likely without appropriate information. Hospital charts, signage, and computerized documents must be quickly accessible, clear, current, consistent, and provide risk-relevant information about patients and potential risk mitigation strategies. Reisig $^{23}$ argued that failure to resolve conflicts between administrators and level-of-care staff is related to poor staff morale, poor cooperation between staff members, and increased patient violence. Cooke and Wozniak ${ }^{5}$ suggested that a negative organizational climate may have a poor commitment to managing violence and breed a tolerance for violence hospital-wide. Examples they provide include senior management rarely entering the units, no identified person assigned to violence management, incomplete or inaccurate written policies related to aggression, and acceptance of risky current practices as long as there was an appearance of calm.

As these existing studies reflect, aspects of ward organization as well as hospital decisions and policies influence the likelihood of violence. Consequently, the second generation of intervention requires treatments that target individual patients, individual wards, and entire hospitals. Just as ecological interventions cannot focus on only one plant species without addressing the soil quality, air content, and water availability, patient aggression cannot be reduced without equal attention to the milieu structure and institutional processes happening simultaneously.

\section{Implementation of an Ecological Based Approach}

Despite these findings, primary focus within psychiatric hospitals remains on treating aggressive patients. Indeed, clinicians are tasked with treating patients and making numerous treatment decisions on a daily basis.
Changes to treatments typically involve conversations between providers, the patient, and possibly family members or legal conservators. However, as long as the proposed treatment follows standard of care, there is typically little involvement from administrative leaders or personnel outside of ward. The second generation of institutional risk management discussed here often requires an integrated approach between administration, clinicians, employee unions, patient's groups, and numerous members of the hospital support staff. The need for so many participants to meet, agree, and cooperate on changes is one of the crucial barriers to implementing an ecological invention for institutional violence. Table 1 lists other barriers to undertaking an ecological approach focused on the ward and the hospital. This table includes barriers due to legal or accreditation requirements, as well as barriers related to hospital culture. Just as each patient presents with a unique constellation of symptoms and social history, each ward and each hospital presents with varying treatment targets and distinctive strengths and weaknesses. Johnstone and Cooke ${ }^{24}$ argue that any hospital attempting to address environmental and situational risk factors must complete an assessment of the symptoms, strengths, and social history of the institution before beginning to implement change.

One DSH hospital has attempted to adopt this ecological view by phasing out an existing risk management strategy, which had been devised by an outside agency, and implementing a new approach. Previously, a review meeting was scheduled after a patient had demonstrated a specified threshold of aggression. At the meeting, 2 clinical team members were asked to

TABLE 1. Potential barriers to implementing an ecological approach to institutional violence

Ward staff and supervisors may have suggestions for safety but no effective way to voice them

- Executive leaders with no accountability for addressing recommendations with proposed changes

- Frequent changes in leadership, at the executive level and on the wards

- Practitioner training focused on new or established treatments for patients

- Employment culture that rewards status quo and does not encourage innovation or creativity.

- Fluctuating budgets and hesitance to spend funds now with no guarantee of future savings

- Prioritizing changes from outside accrediting and legal agencies, typically focused on patient care, patient rights, and maintaining standard of care to the exclusion of internally driven priorities

- Difficulty of creating a treatment environment that promotes safety, patient autonomy, and privacy

- Lack of agreed upon goals and priorities for the facility

- Concern about external criticism from the media, advocacy groups, or unions interfering with attempts to make changes

- Enduring belief that exposure to aggression is one expected pain of institutionalization 
provide short background information about the patient before clinical supervisors and the medical director would discuss the patient's treatment and suggest potential changes to the medication regimen, type of group treatment, or other individualized treatment plans. Although the suggestions stemming from these meetings were often helpful, the meeting focused solely on the patient and the patient's presenting symptoms. With rare exception, the meeting did not include discussion or analysis of the patient's interaction with the treatment environment around him or her.

The new ecological approach continues to use a consultation-style meeting with clinical staff and clinical supervisors; however, there are crucial differences to the new meeting. First, the structure and time allocation of meeting immediately reflects the focus on an ecological view. Only one-third of the meeting is spent discussing the patient's risk factors for aggression, current treatment response, and recommendations for changes to the treatment plan. Each meeting has an assigned facilitator, typically a clinical supervisor, who maintains the meeting structure and keeps the meeting on pace. The second third of the meeting focuses on the features of the ward that potentially escalate or increase the risk for aggression for this particular patient, as well as all other patients living on the ward. The facilitator ensures that this discussion remains neutral, constructive, and broader than the identified patient. The final third of the meeting is devoted to identifying hospital policies or procedures that interfere with building safer wards. Attendance at these new meetings is also broadly representative, and includes many additional key personnel. Instead of just 2 clinical team members, nurses, ward staff, and all clinicians working with the patient participate actively in the meeting to discuss the patient. These meetings also include participants not typically considered part of the treatment team. For example, attendance has also included hospital clergy members, patient's work assignment supervisors, forensic department staff members, the hospital librarian, health and safety officers, and maintenance staff. Anyone who may provide context, information, or solutions to interventions focused on the patient, the ward, and hospital is invited. Although the collaborative nature of meeting remains difficult when there are numerous attendees, the varied expertise is necessary. At a recent meeting, a staff member recommended adding a door to a small room where staff members reported feeling isolated and unsafe. The maintenance staff was able to describe the fire codes and propose alternatives to a door that would meet regulations and provide a safe barrier.

Perhaps most importantly, the tenor and tone of the new meetings is intentionally collaborative. Although envisioned to be supportive, the previous meetings often established a punitive interaction, with supervisors telling clinicians how to change their presumably flawed treatment plan after a patient was aggressive. The new meetings are established as an aid to the ward staff. Staff members are provided the opportunity to openly state the suggestions, frustrations, and concerns they may have kept to themselves or only previously discussed in the break room with colleagues. The facilitator prompts each portion of the meeting with reminders that all ideas and suggestions are welcome. In contrast to the previous meetings, these new ecological approach meetings have been requested by treatment teams prior to incidents of aggression as a preventative measure.

For each meeting, a designated staff member familiar with the philosophy behind the ecological approach takes notes about the factors identified as increasing risk for violence for the individual patient, the ward, and the hospital. These notes are compiled, and a list of recommendations is generated. Table 2 includes recommendations that have been proposed for patients, wards, and the hospital as a whole during these new meetings. The effectiveness of the new process comes after the recommendations have been generated. Administrators dedicated to reducing violence within the hospital prioritize the recommendations in the long-range planning for the hospital and delegate the implementation of new policies or procedures to key personnel. ${ }^{25}$

As these new meetings have gained support from ward staff and administration, they have become even more

TABLE 2. Examples of recommendations based on an ecological approach

- Recommendations based on patient risk factors for violence

- Increase the number of body and locker searches to locate stolen property

- Locate a suitable therapist from psychology or social work departments to begin individual therapy

- Because of the patient's interest in music, identify any additional treatment groups utilizing music

- Refer patient for an updated neuropsychological assessment

Recommendations based on ward risk factors for violence

- Investigate possibility of training ward staff on specialized treatment for patients with developmental disabilities

- Request increased number of staff members during the morning shift

- The current treatment team does not have a psychologist. Prioritize placement of any newly hired psychologist to this ward

- Implement and strictly adhere to a schedule of fresh air breaks, access to the laundry room, and mail call

Recommendations based on facility wide risk factors for violence

- Explore development of a specialized Dialectical Behavior Therapy (DBT) unit

- Analyze the current process for transferring patient from one ward to another and how to improve communication between the previous ward's treatment team and the new ward's clinicians

- Eliminate patient access to the far southeast corner of the outside grounds area where visibility is reduced

- Identify and provide leadership training for newly promoted nursing supervisors that includes positive communication and encouraging management styles, not just progressive discipline policies 
ecological. Now, many meetings are held to discuss broader risk issues facing the hospital, instead of being based on any one patient. Specifically, recent meetings have focused on how to reduce the potential for aggression on a unit with many acutely ill patients or how to eliminate the entry of contraband items (such as drugs or currency) into the locked wards. These issues, which would have not been addressed at the previous type of meeting, are truly ecological in their intent to address risk for increased patient violence by targeting all types of risk, not just a single patient's symptoms.

\section{Conclusion}

Although adoption of these new consultation meetings reflects a commitment to an ecological approach, it remains merely an initial step to significant changes to hospital procedures. Collection of outcome measures, specifically surveys of staff members about their perceptions of the new meetings and assessments of how often recommendations generated at the meetings are addressed, is one of the next steps.

Despite the real barriers that make adoption of this ecological approach difficult, the existing research suggests that a narrow focus on patients' psychiatric symptoms is only part of the solution to reducing violence within hospitals. Indeed, hospitals cannot expect the complex patients admitted to hospitals to recover and become well in polluted, toxic environments.

\section{Disclosures}

Shannon Bader and Sean Evans do not have anything to disclose.

\section{REFERENCES:}

1. Molles M. Ecology: Concepts and Applications. New York: McGraw Hill; 2012.

2. Bronfenbrenner U. Ecological systems theory. In: Bronfenbrenner U. ed. Making Human Beings Human: Bioecological Perspectives on Human Development. Thousand Oaks, CA: Sage Publications Ltd.; 2005: 106-173.

3. Gadon L, Johnstone L, Cooke D. Situational variables and institutional violence: a systematic review of the literature. Clin Psychol Rev. 2006; 26(5): 515-534.

4. Welsh E, Bader S, Evans S. Situational variables related to aggression in institutional settings. Aggression and Violent Behavior. 2013; 18(6): 792-796.

5. Cooke DJ, Wozniak E. PRISM applied to a critical incident review: a case study of the Glendairy prison riot and its aftermath in Barbados. International Journal of Forensic Mental Health. 2010; 9(3): 159-172.
6. Ekland-Olson S, Barrick DM, Cohen LE. Prison overcrowding and disciplinary problems: an analysis of the Texas prison system. Journal of Applied Behavioral Science. 1983; 19(2): 163-192.

7. Mabli J, Holley C, Patrick J, Walls J. Age and prison violence: increasing age heterogeneity as a violence-reducing strategy in prisons. Criminal Justice and Behavior. 1979; 6(2): 175-186.

8. Palmstierna T, Huitfeldt B, Wistedt B. The relationship of crowding and aggressive behavior on a psychiatric intensive care unit. Hosp Community Psychiatry. 1991; 42(12): 1237-1240.

9. Flannery RB Jr, Hanson MA, Penk WE. Risk factors for psychiatric inpatient assaults on staff. J Ment Health Adm. 1994; 21(1): 24-31.

10. Flannery RB, Staffieri A, Hildum S, Walker AP. The violence triad and common single precipitants to psychiatric patient assaults on staff: 16-year analysis of the Assaulted Staff Action Program. Psychiatr Q. 2011; 82(2): 85-93.

11. Davies W, Burgess PW. Prison officers' experience as a predictor of risk of attack: an analysis within the British prison system. Med Sci Law. 1988; 28(2): 135-138.

12. Webster CD, Nicholls TD, Martin ML, Desmarais SL, Brink J. ShortTerm Assessment of Risk and Treatability (START): the case for a new structured professional judgment scheme. Behav Sci Law. 2006; 24(6): 747-766.

13. Hamadeh RR, Al Alaiwat B, Al Ansari A. Assaults and nonpatientinduced injuries among psychiatric nursing staff in Bahrain. Issues Ment Health Nurs. 2003; 24(4): 409-417.

14. Flannery RB Jr, White DL, Flannery GJ, Walker AP. Time of psychiatric patient assaults: fifteen-year analysis of the Assaulted Staff Action Program (ASAP). Int J Emerg Ment Health. 2007; 9(2): 89-95.

15. Flannery RB Jr. Precipitants to psychiatric patient assaults on staff: review of empirical findings, 1990-2003, and risk management implications. Psychiatr Q. 2005; 76(4): 317-326.

16. Bader SM, Evans SE, Welsh E. Aggression among psychiatric inpatients: the relationship between time, place, victims and severity ratings. J Am Psychiatr Nurses Assoc. 2014; 20(3): 179-186.

17. Quanbeck CD, McDermott BE, Lam J, Eisenstark H, Sokolov G. Categorization of aggressive acts committed by chronically assaultive state hospital patients. Psychiatr Serv. 2007; 58(4): 521-528.

18. Flannery RB Jr, Hanson MA, Penk WE, Flannery GJ. Violence and the lax milieu? Preliminary data. Psychiatr Q. 1996; 67(1): 47-50.

19. Morrison E, Morman G, Bonner G, Taylor C, Abraham I, Lathan L. Reducing staff injuries and violence in a forensic psychiatric setting. Arch Psychiatr Nurs. 2002; 16(3): 108-117.

20. Katz P, Kirkland FR. Violence and social structure on mental hospital wards. Psychiatry. 1990; 53(3): 262-277.

21. Baldwin S. Effects of furniture rearrangement on the atmosphere of wards in a maximum-security hospital. Hosp Community Psychiatry. 1985; 36(5): 525-528.

22. Zaslove MO, Beal M, McKinney RE. Changes in behaviors of inpatients after a ban on the sale of caffeinated drinks. Hosp Community Psychiatry. 1991; 42(1): 84-85.

23. Reisig MD. Administrative control and inmate homicide. Homicide Studies. 2002; 6(1): 84-103.

24. Johnstone L, Cooke DJ. PRISM: a promising paradigm for assessing and managing institutional violence: findings from a multiple case study analysis of five Scottish prisons. International Journal of Forensic Mental Health. 2010; 9(3): 180-191.

25. Braz R. Enterprise risk management: Part one: defining the concept, recognizing its value. J Healthc Risk Manag. 2005; 25(4): 11-13. 